\title{
Public Accountability towards Entrepreneurship Development in India
}

\section{* Dr. Shailendra Kumar}

Abstract

Entrepreneurship has significant role in economic development and social transformation. However, India is lagging behind in skill and entrepreneurship development as hardly 3 per cent of the work force has achieved some kind of vocational education. Though, India has a vast network of technical and professional education institutions however, it faces a huge deficit of skilled human resources. Entrepreneurship development and training is, thus, one of the key elements for development of micro and small enterprises (MSEs), particularly, for the first generation entrepreneurs. The present paper has highlighted the public accountability towards entrepreneurship development in India.

Key Words: Entrepreneurship, Accountability, Skill Training, Socialization

\section{Introduction}

Entrepreneurship has been considered as the backbone of economic development. It has been well established that the level of economic growth of a region, to a large extent, depends on the level of entrepreneurial activities in the region. The myth that entrepreneurs are born, no more holds truth, rather it is well recognized now that the entrepreneurs can be created and nurtured through appropriate interventions in the form of entrepreneurship development programmes. In the era of liberalization, privatization and globalization along with ongoing Information Technology revolution, capable entrepreneurs are making use of the opportunities emerging from the changing scenario. However, a large segment of the population, particularly in the industrially backward regions generally lags behind in taking advantage of these opportunities.

* Post Doctoral Fellow (UGC) , Deptt. of Sociology, Lucknow University, Lucknow 
Therefore, there is a need to provide skill development and entrepreneurship development training to such population in order to mainstream them in the ongoing process of economic growth and development.

\section{Conceptualization of Entrepreneurship}

Entrepreneurship means different things to different people. Conceptually and in practice, the term hints of no stereotypical model. Yet its very etymology - derived from the French 'entreprendre which literally means, 'to undertake' - indicates the minimum characteristics of an entrepreneur (National Knowledge Commission, 2008). From the perspective of economic functions, three crucial characteristics of entrepreneurial activity are: risk taking, innovation and venturing into new business activities for profit. National Knowledge Commission (2008) has defined entrepreneurship as the professional application of knowledge, skills and competencies and/or of monetizing a new idea, by an individual or a set of people by launching an enterprise or diversifying from an existing one, thus to pursue growth while generating wealth, employment and social good'.

\section{Role of Entrepreneurs in Economy}

The concept of entrepreneurship is not different in developing economies. In development economies like India the scope and need of entrepreneur is higher. An entrepreneur needs not necessarily innovate, even if he imitates any technique of production / marketing from a developed country, he makes a contribution to economic development as long as he starts business, undertakes risk and bears uncertainties. In developing countries entrepreneurship is considered as a form of labour, which directs the rest of labour what to do and how to get things done (World Bank, 2007). Entrepreneurship development in India has received much attention during the last few years. In the Industry Policy Resolution of 1956, the government had emphasized the setting up of large number of medium and smallscale industries as one of the major steps for the economic growth of the country and to solve the massive unemployment problem among 
the educated youth of the country.

Despite the critical importance of entrepreneurs and entrepreneurship, few developmental programmes or strategies include systematic means for identifying entrepreneurial potential and enhancing that potential, or for stimulating new sources of entrepreneurship programmes. Financial institutions have excellent systems for assessing collaterals, mediocre systems for assessing project feasibility but no system at all for assessing entrepreneurial acumen. Numerous management training programmes have been developed for strengthening accounting skills, feasibility analysis, marketing and inventory control but few of these programmes address the fundamental question of how to select and strengthen entrepreneurs and their business plan (Utz, 2005). The entrepreneur who implements 'new combinations of means of production' plays a crucial role in disturbing the status quo through innovation - or 'creative destruction' - and thereby becomes an agent of change. As such, the 'dynamic equilibrium' achieved by a constantly innovating entrepreneur could generate the conditions for (National Knowledge Commission, 2008): (1) increasing opportunities for employment (comprising various competitive skill sets); (2) additional wealth creation; (3) introduction and dissemination of new methods and technology; and (4) overall economic growth. It is in the creation of more wealth, and in the constant innovation from prevailing to the next best practices, that the significance and importance of entrepreneurship lies. As such, the development of entrepreneurship in a particular milieu depends not on a single overriding factor but rather on 'a constellation of factors' at the individual, societal and national levels (Tripathi, 1984). Entrepreneurship depends on individual motivations, individual experiences, socio-cultural traditions, educational opportunities, availability of relevant skills and attitudes, supporting financial institutions and access to credit, existence of commercial trading centres, supporting infrastructure including trade routes with efficient transport and communication facilities, macro-economic environment and overall political stability. It has also been argued that Innovation and Entrepreneurship flourish best in decentralized systems by 
empowered people, who are willing to explore new ideas as well as willing to deal with exogenous influences.

\section{Accountability Initiatives}

Schedler (1999) defines public accountability as "the relationships between the power holder and delegator." There are four key elements of an accountability relationship which include setting standards, acquiring information about actions, making decisions about appropriateness and identifying and sanctioning unsatisfactory performance (Joshi, 2010,). As with the transparency literature, however, the accountability literature does not identify which of these elements are essential for a particular initiative to be considered robust. It is noted that often some, but not all of these four components can be found and have an impact on public services. Also as with transparency literature, there is an element of directionality, as accountability is either considered horizontal or vertical (Goetz and Jenkins, 2001).There is many state-led and citizen-led initiatives that demand accountability in service delivery. Multiple stakeholders demand accountability of politicians who are not adopting appropriate policies. Additionally accountability is demanded of public officials who are not delivering services according to rules or entitlements or not monitoring providers for appropriate service levels. Finally accountability is demanded directly of providers for not maintaining service levels in terms of access and quality (Davis, 2004; Joshi, 2010). However, as with transparency, the concept of accountability can be critiqued and interpreted in several ways. Firstly, Goetz and Jenkins (2001) argue that horizontal accountability is largely unsuccessful, and more powers should be given to citizens to ensure political accountability, as elections have their own shortcomings. They go on to argue that where citizen participation is incorporated into horizontal accountability, more powerful hybrid forms of accountability emerge. Secondly, it is argued that although accountability may be understood in instrumental terms, such as the monitoring and planning of public service delivery, as identified above, there also needs to be greater consideration of what exactly accountability means. As with transparency, accountability is a social 
construct, consisting of the attitudes, relationships, power structures and norms of the organization being accounted for (Roberts, 1991; Mulgan, 2000). These local interpretations of accountability are critical if we are to understand how accountability can be institutionalized. If accountability is an external requisite, not integrated with an entire government process from initiation to evaluation, it is unlikely to be more than superficial information gathering and consultation (Paul, 1992; Vigoda and Golembiewski).

\section{Public Accountability}

Accountability is one of those golden concepts that no one can be against. It is increasingly used in political discourse and policy documents because it conveys an image of transparency and trustworthiness. However, its evocative powers make it also a very elusive concept because it can mean many different things to different people, as anyone studying accountability will soon discover. This paper nevertheless tries to develop an analytical framework for the empirical study of accountability arrangements in the public domain. It starts from a narrow, relational definition of accountability and distinguishes a number of indicators that can be used to identify and classify accountability arrangements. Furthermore, it develops three perspectives to assess and evaluate accountability arrangements in the public domain. A great many social relationships carry an element of accountability within. However, this paper solely concerns public accountability. 'Public' relates in this respect to a number of different aspects. In the first place, used in this context, 'public' should be understood to mean 'openness'. Account is not rendered discretely, behind closed doors, but is in principle open to the general public. The information provided about the actor's conduct is widely accessible, hearings and debates are open to the public and the forum broadcasts its judgement to the general public. In the second place, 'public' refers to the object of the account to be rendered. Public accountability mainly regards matters in the public domain, such as the spending of public funds, the exercise of public authorities, or the conduct of public institutions. It is not necessarily limited to public organisations, but 
can extend to private bodies that exercise public privileges or receive public funding (Scott 2000). This also impacts on the accounting perspective. Public accountability implies the rendering of account for matters of public interest, i.e. an accounting that is performed with a view to the judgement to be passed by the citizens. In general, one could say that public accountability is accountability in and about the public domain.

\section{Social Accountability}

Social accountability has been defined as "an approach towards building accountability that relies on civic engagement, i.e., in which it is ordinary citizens and/or civil society organizations who participate directly or indirectly in exacting accountability" (Malena, Forster and Singh, 2004). The mechanisms for implementing this form of accountability are 'vertical.' Although elections have a similar role, they are considered a 'blunt instrument' as they do not enable citizens to state their preferences regarding specific issues, participate effectively in public decision making or hold public officials accountable for particular decisions and behavior. Examples of social accountability initiatives include 'traditional' forms, such as public demonstrations, advocacy campaigns, investigative journalism; and, the recent ones such as citizen report cards, participatory public policy making, public expenditure tracking, and "efforts to improve the effectiveness of "internal" accountability mechanisms of the government, for example by involving citizens in public commissions and hearings and oversight committees." (Malena, Forster and Singh, 2004) It has also been suggested that social accountability initiatives are most effective when these are 'institutionalized' and when the states' 'internal' (horizontal) accountability mechanisms are "more transparent and open to civic involvement." Thus, transparency is inextricably linked to accountability. Poor people are the greatest beneficiaries of effective social accountability initiatives as they are the "most reliant on government services and least equipped to hold government officials accountable" (Malena, Forster and Singh, 2004). The proponents of social accountability maintain that by involving citizens in initiatives 
geared towards demanding accountability of elected leaders, social accountability also strengthens democracy. The monitoring of government performance and demand for transparency protects against corruption. A key feature of recent practices is the increased reliance on civil society organizations (CSOs) - through domestic imperatives or externally driven donor support-to influence government priorities for spending and reform and monitoring public expenditures. These models have originated from different sources in response to various problems. Recent practices implementing the concepts of social accountability include, among others, participatory budgeting, public expenditure tracking, monitoring of public service delivery, investigative journalism, public commissions and citizen advisory boards. A key feature of such practices is the increased reliance on CSOs - to influence government priorities for spending and reform, and monitoring public expenditures. Some of the best models have arisen at the local level, either from civil society or local government usually with external donor support, and signal the importance of reaching down to local levels for innovation.

\section{Social Entrepreneurship Development}

Social Entrepreneurs endeavor to "create social" value through innovative, entrepreneurial business models. The potential market for these entrepreneurs is huge because of the wide range of social needs that remain unsatisfied by existing markets and institutions. Social entrepreneurs often create tremendous value when they cater to very basic humanitarian needs; for example, by providing medicines or food, which can be a matter of life or death for those who receive them. However, the challenges these entrepreneurs face are severe. Their "customers" may be willing, but often unable, to pay even a small portion of the cost of the products and services provided. Many social entrepreneurs operate in developing countries that have no structures or resources that would enable and support traditional entrepreneurship (Seelos et. al, 2004).

As a consequence these social entrepreneurs must create fresh business models and organizational structures, which connect 
profitable existence to social value. Social entrepreneurship (SE) may provide some enthralling new insights and supplement designs for more socially suitable and sustainable business strategies. They discover new and competent ways to create products, services or structures, thus enabling them to cater to social needs to accomplish sustainable development. Entrepreneurship is consequence of an opportunity recognition and orientation, while accounting the characteristics of the individuals involved who are highly motivated. Conventionally, most people would connect entrepreneurship with the quest of a business opportunity in order to make a living and in the case of social entrepreneurship the business opportunity is a social need that cannot be fulfilled by either markets or social systems. Entrepreneurs are determined to do no matter what it is in their influence to do to accomplish their goals. Their very nature of being flexible, creative and inventiveness produce tremendous performance in exercising their idea into outcome.

Social Entrepreneurs distinguish themselves from other individuals by the very nature of their concerns for serving for a social cause. They possess "entrepreneurial quality" and at the same time have respect for their surroundings. At times social entrepreneurs do not even know of their own presence, until they are recognized by people or organizations. Major global issues that attract social responsibility are eradication of poverty and hunger, universal primary education, entrepreneurship development, livelihood development, promoting equality and empower women, ensuring environmental sustainability and green presence and developing a global partnership for interdependent development. Hence to carry forward this mammoth task, the Enterprises will have to evolve an innovative process or system that would perhaps provide it an edge over its competition. It has to be evolved and cannot be replicated. Thus it is necessary to research why some enterprises are able to create more value than others (Joshi, et. al., 2007).

\section{Demand for Skill Training in India}

According to Economic Survey, 2007-08, 64.8 per cent of India's population would be in the working age of 15-64 years in 2026 up 
from 62.9 per cent in 2006 (Government of India, 2008). A study conducted by Confederation of Indian Industry and Boston Consulting Group reported that demographic shift is likely to happen in favour of working age group. About 109 million persons are likely to attain working age during 2007-12 (CII, 2005). The net addition to work force is expected to grow to 89 million of which around 13 million are likely to be graduates / postgraduates and about 57 million are likely to be school drop outs or illiterates. The study further estimated that India is likely to increase deficit of 5.25 million employable graduates and vocationally trained workforce by 2012 (Government of India, 2009).

In order to impart skills that are relevant to the market, a key challenge is enabling the individual to take advantage of available opportunities. The Confederation of Indian Industry has projected the following requirement of skilled workers at different levels by 2015. Further, there is an acute shortage of trained manpower in the hospitality sector. It is observed that the annual requirement of the trained manpower in the hospitality sector is about 2.03 Lakhs. Against this, the supply is only about 12000 . Keeping in view the ratio of requirement of managers and skilled personnel as about 34:66, it is estimated that about 1.34 Lakhs skilled persons, below managerial level, will be required in the hospitality sector. The total requirement of skilled work force by 2022 is estimated at about 300 Million, including a huge number at the lower end and indicating large scale opportunities likely to be offered to the poor by the market - at the bottom of the pyramid. Escalating urbanization will also create many opportunities in the unorganized sector arising from the economies of agglomeration.

While India has improved its performance in education however, there is growing deficit of skilled manpower (Clark, 2005). The education and skills provided must be relevant to the labour market. The existing infrastructure in public sector for providing vocational training and entrepreneurship skills to the growing demand is found to be grossly inadequate (Clark, 2003). Thus, there is need to augment resources and promote public private partnership to provide 
vocational training and entrepreneurship development to the youth. Since about 90 per cent of employment in India is in the informal sector, with employees working in relatively low productivity jobs, there is imperative need to strengthen the educational infrastructure and mobilizing private sector for public private partnership to meet the diverse skill needs of the informal sector (World Bank, 2006). In order to provide skill training and entrepreneurship development to the workforce, India has set a target of skilling 500 million people by the year 2022. Each State is expected to identify potential employers in cities and towns and at local, district and regional level. Sectors might include ITEs, manufacturing, construction, sales and marketing, education, health and fitness, logistics management, financial sector, office automation/management, hospitality, visual arts, gems and jewelry, health care, repairs and maintenance, tourism and adventurous sports, life styles, etc. Making a list of the employers and setting up a dialogue with sector/industry associations would be the first step to understand the skill training needs and likely number of jobs (Singh, 2009).

\section{Entrepreneurship in India}

Entrepreneurship has been 'embedded in the Indian genius and is a part of its tradition'. The renowned economist, T.N. Srinivasan, has remarked that 'India has been an entrepreneurial society. We had the entrepreneurial skill but suppressed it for too long a time and now it is thriving' (Srinivasan, 2007). The entrepreneurial spirit is an ongoing characteristic of India's history, particularly visible in a number of communities engaged primarily in trading. Traditionally, the entrepreneurship of such communities is facilitated principally by the successful use of informal 'entrepreneurial ecosystems' and interdependent business networks. Further, there is also a rich tradition within the Indian diaspora, spanning the past several hundred years, whose spirit of enterprise is legion. Recent surveys undertaken by Goldman Sachs and Price Water house Coopers, have estimated that India has the potential to be among the world's leading economies by 2050 (Outlook Business, May 5, 2007). Further, India's economy can potentially gain significantly from the country's 
characteristic features - a democratic open society, a strong technology base, unparalleled diversity, vibrant capital markets, an increasingly youthful population, a sizeable market of a large number of customers with vast unmet needs as well as an environment of full and free competition in the private sector (Gobind Rajan, 2007)

India has enormous potential for creation of wealth through knowledge. Entrepreneurship and innovation are the key drivers for generating wealth from knowledge, supported principally by the availability of skilled human resources, access to finance and ability of the government to create an enabling environment (National Knowledge Commission, 2009). The Entrepreneurship 'Pyramid' in India is illustrated to understand the type of sectors in which entrepreneurship takes place in India:

- Level 1: Agriculture and other activities: Crop production, Plantation, Forestry, Livestock, Fishing, Mining and Quarrying.

- Level 2: Trading services: Wholesale and retail trade; Hotels and restaurants

- Level 3: Old economy or traditional sectors: Manufacturing, Electricity, Gas and Water supply

- Level 4: Emerging sectors (including knowledge intensive sectors): IT, Finance, Insurance and Business services, Construction, Community, Social \& Personal Services, Supply Chain, and Transport-Storage-Communications etc.

In order to illustrate the reasons for becoming an entrepreneur, National Knowledge Commission (2008) has highlighted the following points:

- 'Entrepreneurship offers the opportunity to create something of one's own'.

- 'Entrepreneurs get the opportunity to make the road as well as walk on it'.

- 'Entrepreneurship allows people to think outside the box and make thoughts work'. 
- 'Entrepreneurs are not confined to a particular area of business; they need to know everything about how business runs'.

- 'Entrepreneurship allows possibilities for constant selfactualization'.

- 'Entrepreneurship is about the ability to survive long enough till one succeeds'.

- 'Entrepreneurship is about the sheer joy of taking an idea and making it work'.

- 'Entrepreneurs are like lotuses - born out of dirt - and all they need is a flourishing environment'.

- 'Entrepreneurs like to do it their way - they are virtually unemployable'.

- 'Entrepreneurship brings pride, passion and self-respect, from doing things on one's own'.

- 'Entrepreneurship gives the freedom to try something new and break stereotypes'.

- 'Entrepreneurship provides a constant learning experience and a continuous process of growth'.

- 'Entrepreneurship brings a sense of belongingness derived from doing one's own thing and providing employment to many'.

- 'Entrepreneurship provides the opportunity to create wealth and make the best of the economic environment'.

Socio-cultural factors such as social norms, family values, networks and social values of entrepreneurship play a key role in nurturing the entrepreneurial eco-system. Tripathi (1984) has illustrated the 'constellation of socio-cultural forces' that has been responsible for the development of business enterprise in certain communities comprises the following:

Credit Facilities: The existence of community banks and credit networks (including profit-sharing schemes) has traditionally ensured availability of liquidity. While describing the Sarafi System used by Marwaris in Benaras, Alan R. Cohen remarked as follows: 'Firms in the system borrowed from each other whenever short of 
cash, loans were payable on demand, "even at midnight" and interest was tallied and settled once a year, with total borrowing offset by total lending."

Infrastructural Support: Traditional networks assure infrastructural support such as access to storage facilities for goods along trade routes, remittance facilities and arrangements for accommodation. Thomas Timberg, for example, cites how G.D. Birla's grandfather, Shiv Narain, stayed in a cooperative 'basa' (collective mess) in the Bombay when he first arrived from his village of Pilani in the $1860 \mathrm{~s}$.

Socialization: The community encourages socialization into Entrepreneurship, the inculcation of commercial morality (respecting the contract, making ethical profits etc), notions of thrift as well as training opportunities, such as apprenticeships to learn techniques of business. Mechanisms for 'cushioning of conflict' and division of labour and authority also develop through the joint family system and social networks.

Market Development: In certain geographical locations, the presence of entrepreneurial communities led to the development of futures markets. Further, migration of the community (e.g. the Marwaris) to commercial centres such as ports and trading hubs encouraged Entrepreneurship in these places.

Vocational Education \& Training - Skill Development: It is pertinent to note that only 5 per cent of India's existing workforce has received skill training as against 96 per cent in Korea, 75 per cent in Germany, 80 per cent in Japan and 68 per cent in United Kingdom (Government of India, 2006). Vocational education and training need to be given high priority in India. Skill development is crucial to reap the demographic dividend in India, where the size of the working age population, as per the annual budget 2008-09, is estimated to increase from 77.5 crore in 2008 to 95 crore in 2026. National Knowledge Commission has recommended the need for grassroots reforms in this area, such as innovative delivery models, re-branding, improving certification and monitoring as well as increasing flexibility of vocational education and training with the school and higher 
education streams. Currently, there is stigma associated with vocational education and training as a result of various systemic flaws, such as the following (National Knowledge Commission, 2008):

- Returns from vocational education and training are low and the quality of training does not meet the needs of industry.

- There is little incentive to pursue vocational education and training courses since most of these do not lead to a job.

- Facilities in most vocational education and training institutes are old and outdated.

- Different aspects of vocational education and training are in the hands of different ministries and therefore vocational education and training has become a 'policy orphan'.

- There is lack of any assessment of skills and requirements at the entry stage itself.

- There is need to provide incentives for training in spoken and written English.

- Performance outcomes in vocational education and training institutions are not measured with industry participation and there is no incentive for better performance.

- Current certification systems are inadequate and in need of overhaul. The emphasis should be on designing institutional systems that are 'accreditation-light' and 'certification-heavy', focusing more on empowering the student for a variety of industry needs.

\section{Infrastructure of Entrepreneurial Skills}

Technical workforce needs highly level knowledge and skills to deal with fast changing technologies in order to successfully complete in the global level market. The technical education covers courses and programmes, inter-alia, in engineering, technology, management, architecture, town planning, pharmacy, applies arts and crafts, hotel management and catering technology. As on $30^{\text {th }}$ June, 2009, there were 7272 technical institutions including management institutions 
with an intake of 14.10 lakh for degrees and 2324 diploma level institutions with a total enrolment of 5.08 lakh students. Thus, the total technical education enrolment at 19.18 lakh accounts for only 9.48 per cent of total higher education enrolments. The number of AICTE approved technical institutions has increased from 5269 at the beginning of the $11^{\text {th }}$ Plan to 9596 as on June, 2009. These comprise 2872 engineering and technology colleges, 1659 polytechnic, 1080 institutions for degree and 575 institutions for diploma in pharmacy, 179 schools for degree as well as diploma in hotel management, 16 institutions for art and craft and 106 institutions for architecture. There are 1940 educational institutions for MBA, PGDM and 1169 for MCA. The intake of students at undergraduate level in existing 7 IITs at Delhi, Mumbai, Kanpur, Khadagpur, Chennai, Guwahati and Roorkee has increased from 4977 in 2008-09 to 5464 in 2009-10. The government has approved setting up of 8 new IITs in the states of Andhra Pradesh, Bihar, Rajasthan, Orissa, Punjab, Gujarat, Madhya Pradesh and Himachal Pradesh. The total intake of existing 7 IIMs has increased by 17 per cent from 1426 in 2007-08 to 2100 in 2009-10. The government has approved the setting up of ne IIMs in the states of Tamil Nadu, Jharkhand, Chhattisgarh, Uttarakhand, Haryana and Rajasthan. In addition to the existing 20 National Institutes of Technology with an annual intake capacity of about 15,000 in engineering and related subjects, 10 more NITs have been approved under the $11^{\text {th }}$ Plan and will be set up in Arunachal Pradesh, Manipur, Meghalaya, Mizoram, Nagaland, Goa, Pondicherry, Sikkim, Delhi and Uttarakhand. The government has also approved 20 new IIITs in PPP mode during the $11^{\text {th }}$ Plan. The government has also approved setting up 1000 new polytechnics, besides strengthening ad upgradation of about 500 existing polytechnics (Government of India, 2011).

As another step towards skill development initiative, government has proposed to set up 1500 new industrial training institutes and also 50,000 skill development centres. These centers are to be set up by various Ministries and Departments. There are 8039 industrial training institutes and industrial training centres imparting training in 
114 engineering and non-engineering trades. The total sitting capacity in these ITIs is 11.15 lakh. In addition, the current Plan has targeted setting up 30 new Central universities, eight new Indian Institutes of Technology (IITs), seven new Indian Institutes of Management (IIMs), 10 new National Institutes of Technology (NITs), three Indian Institutes of Science Education and Research (IISERs), 20 Indian Institutes of Information Technology (IIITs) and two new Schools of Planning and Architecture (SPA) and number of new degree colleges (Government of India, 2006). For upgrading science education and research infrastructure in the universities, it is envisaged that the existing Science and Engineering Research Council (SERC) mechanism of the Department of Science and Technology should be restructured to constitute a National Science and Engineering Research Board (NSERB). The NSERB would aim at expanding and strengthening the $\mathrm{S} \& \mathrm{~T}$ base in the universities, building research capabilities in the academic sector and ensuring funding for undertaking internationally competitive research programmes (Government of India, 2006).

The Eleventh Plan also aims to launch a National Skill Development Mission (NSDM) and has proposed to allocate Rs. 31,200 crore for this. In the annual budget for 2008-09, the Government of India has proposed the establishment of a non-profit corporation, to fulfill the NSDM goals, with about Rs. 15,000 crore as capital from various sources, public and private, and an initial government equity of Rs. 1000 crore. During the Plan period, the mission is expected to spearhead efforts to increase the number of trained personnel from 2.5 million to 10 million. It is expected to coordinate the relevant vocational education and training work of 17 different ministries and departments of the Government of India, involve the private sector and facilitate a collaborative process. The Public Private Partnership (PPP) mode is expected to restructure and reposition existing infrastructure, with coordination from concerned ministries. Further, in 20 identified high growth sectors, private initiatives with government support are also planned. Respective industry associations in each sector are expected to outline their vision for the 
'Sectoral Skill Development Initiative' (SSDI). The NSDM would engage with each of these sectors to work out appropriate deliverables and strategies in the respective 'Sectoral Skill Development Plans'. It would then prescribe a national framework for domain-specific standards and common principles to create an enabling environment for private investment in skill training. Further, the NSDM has an action plan for the Ministry of Rural Development under which 600 new RUDISETIs (Rural Development and Self Employment Training Institutes) would be set up. These RUDISETIs are expected to focus on developing entrepreneurship by collaborating with the Entrepreneurship Development Institute (EDI), which is an autonomous non-profit organization set up to promote entrepreneurship through education, research and training (www.ediindia.org).

In India, in order to develop techno-preneurship, the Ministry of Science and Technology (MoST) initiated the Science and Technology Entrepreneurship Park (STEP) programme under the National Science and Technology Entrepreneurship Development Board (NSTEDB) in 1984 in collaboration with financial institutions such as IDBI, IFCI and ICICI. STEP has tried to foster linkages between academia, industry and R\&D institutions to inculcate a culture of Entrepreneurship (www.unescap.org). Other ministries today supplement MoST's pioneering efforts and the private sector is also entering the incubation space. Another initiative envisaged is the Technology Incubation Development of Entrepreneurs (TIDE) under the Department of Information Technology (DIT). A fund worth Rs. 25 crore is proposed to be set up, from which selected start-ups will receive a funding of Rs 25 lakh to Rs 50 lakh per startup for a twoyear period. This initiative will also be promoted through premier institutions such as the Indian Institute of Science (IISC), the Indian Institutes of Technology (IITs) and the Indian Institutes of Management (IIMs). Further, the ISBA (The Indian STEP and Business Incubator Association) was set up in 2004 to serve as a professional apex body to promote business incubation in India. 
Table No. 1: State-wise Entrepreneurial Confidence Index

\section{Skill Development Initiative Scheme}

The skill development initiative scheme was launched in 2007 which aims at providing vocational training to school leavers, existing workers, ITI graduates, etc., to improve their employability by optimally using the existing infrastructure available in government, private institutions or industry. Exiting skills can be tested and certified under the scheme which primarily aims at development of competency standards, course curricula, learning material and assessment standards in the country. Since its inception, 5203 government/private and other vocational training providers have 
been registered and 467277 persons have been trained, tested and certified along with the development of 1108 course modules for employable skills covering 48 sectors. Inclusive growth in India requires equal opportunities and entrepreneurship has the potential to meet this demand. Entrepreneurship is a crucial element of a growing economy. Indian entrepreneurial culture has come a long way during last decade as Indian entrepreneurship not only have global plans but also have ability to execute those plans efficiently. As Indian entrepreneurial ventures continue to play a major role in sustaining the country's growth, it is critical to assess the conduciveness of the business eco-system in India (SHRM, 2011). A study conducted by KPMG (2008) has calculated entrepreneurial confidence index in India. Andhra Pradesh, Goa, Rajasthan, Maharashtra, Gujarat, Tamil Nadu and Punjab have weighted average scores higher that the national average while Chandigarh, Karnataka, Madhya Pradesh, Uttar Pradesh, Haryana, Kerala, West Bengal and Delhi have been rated below the national average scores (Table No. 1).

Table No. 2 : Preferred Entrepreneurial Destinations 
The study with a sample of more than 1000 entrepreneurs conducted by KPMG (2008) has demonstrated that Gujarat topped the list with a whopping 23.3 per cent respondent base preferring the state for setting up their entrepreneurial venture. Next in the line was Maharashtra with a 13.4 percent preference followed by Haryana with 7.5 per cent and Delhi following with 5.5 per cent respondents preferring the state (Table No. 2).

\section{Conclusion}

Entrepreneurship development and training is, thus, one of the key elements for development of micro and small enterprises (MSEs), particularly, for the first generation entrepreneurs. In order to undertake this task on regular basis, the government has set up three national-level Entrepreneurship Development Institutes (EDIs). These are the National Institute for Micro, Small and Medium Enterprises (NI-MSME), Hyderabad; the Indian Institute of Entrepreneurship (IIE), Guwahati and National Institute for Entrepreneurship and Small Business Development (NIESBUD), Noida. Further, the government has been implementing Scheme for Assistance for Strengthening of Training Infrastructure of Existing and New Entrepreneurship Development Institutes (EDIs). The main objectives of the scheme are (i) promoting entrepreneurship for creating self-employment through enterprise creation; (ii) facilitating creation of training infrastructure; and (iii) supporting research on entrepreneurship related issues. In view of the growing importance of skill training and entrepreneurship development, Government of India has launched National Skill Development Mission and National Skill Development Policy. The national policy on skill development envisages to creating opportunities for all to acquire skills throughout life and especially for youth, women and disadvantaged group, promoting commitment by all stakeholders to own skill development initiatives, developing a high quality skilled workforce, entrepreneurs relevant to emerging employment market needs. The policy has widened the scope of skill training and entrepreneurship development through utilizing the existing educational infrastructure and expansion of institutions engaged in 
skill training and vocational education. Government of India has also introduced several schemes, programmes and projects for providing training, vocational education and entrepreneurship development to youth, women and disadvantaged groups. The SHG-based micro financing and livelihood development programmes also focus on providing training, entrepreneurship development and skill up gradation among women so that micro economic enterprises initiated by them may sustain. Public accountability towards entrepreneurship development is imperative as poverty alleviation and livelihoods development for the poor, marginalized, and weaker sections of society may be ensured through promoting corporate social responsibility initiatives, accountability in administration, and promoting social entrepreneurship. Public accountability in promotion of entrepreneurship is also necessary for creating employment opportunities to them who have been provided entrepreneurship training.

\section{Suggestions}

- Understanding the business environment, demand for products and services, availability of raw materials, technology, investment and other inputs of industrial development is necessary before setting up the enterprise. Therefore, feasibility studies should be conducted by the academic, financial, government and other institutions so that women entrepreneurs may mentally prepare for setting up their business enterprise.

- Hard work, persistence, perseverance and confidence are some of the qualities of entrepreneur, however, understanding of prevailing business environment, cost effective production technologies, suitable marketing strategies, managerial efficiency are also important attributes of entrepreneurs.

- In order to ensure proper facilitation and guidance to entrepreneurs, improvement in the current Single Window System of getting clearances is imperative while introduction of a Single Composite Application Form is required to facilitate women entrepreneurs.

- It is imperative to develop a comprehensive Incubation Policy at 
the national level, which would increase quantity, enhance quality and increase access to financing to entrepreneurs. Government should set up a Global Technology Acquisition Fund in Intellectual Property (IP), which could enable crucial technology acquisition across the world, especially for SMEs.

- Government should introduce specific skill oriented courses in schools, colleges and universities for promoting vocationalization of education. In order to promote vocational education, in backward and remote areas, there is a need to tie up with colleges, technical institutions, NGOs and other academic institutions however, accreditation with state and national level institutions may be given to ensure the quality of vocational education and skill training.

- New trades of entrepreneurship education, skill training and technical knowledge should be explored through market survey. The new trades of skill training should be suited to women, sociocultural environment and the market demand.

- Public private partnership should be further encouraged to provide skill training, entrepreneurship development and vocational education. The corporate houses should be mobilized who have joint ventures with government and academic institutions to provide vocational education, entrepreneurial skills and technical knowledge for livelihood development.

- There should be proper coordination and networking among the various stakeholders engaged in skill training, vocational education and entrepreneurship development so that convergence of services programmes, schemes and resources may be ensured..

- Micro credit programmes must include strategies and budgetary allocation for building the capacity of SHGs, their members and federation of SHG to manage savings and credit, augment vocational skills and promote enterprise. Skill training programmes should be linked with market analysis, credit provision, income generating activities and market exposure.

- There is urgent need to streamline the procedure for applying, 
seeking and releasing of credit from the banks. The procedural difficulties are one of the major impediments which are denied women the financial benefits of the banks. Therefore, the procedure for credit access should be made more easy and simple.

- Government should set up common facility centre, micro business centre, advisory and consultancy services, etc. in the industrial and business clusters so that the interested women may be provided skill training, entrepreneurship development and proper guidance for starting up business enterprises.

- ICT interventions may be very fruitful in promotion, development and growth of the small business. Even such interventions may provide opportunities for socio-economic empowerment of artisans and workers. Skill up-gradation, craft development, technology transfer, developments of printing, designing and innovative styles etc. may be ensured through it. These interventions are supposed to provide excellent opportunities for employment generation, marketing of products and particularly creating export demand.

- Strengthening the infrastructure to facilitate the all round development of the small and micro business is the need of hour. This requires development of adequate infrastructure such as roads, connectivity power, transportation etc. Giving piloting role in establishing infrastructure in the state may encourage private sector.

\section{References}

CII (2005), Managing ITIs, Confederation of Indian Industries, New Delhi.

Clark, P. (2003), Secondary Education in India, Working Paper, World Bank, New Delhi.

Clark, P. (2005), Technical and Vocational Educational Systems in Australia and India: An Experiment in Cross Cultural Learning, World Bank Paper, World Bank, New Delhi.

Davis, J. (2004). Corruption in Public Service Delivery: Experience from South Asia's Water and Sanitation Sector. World Development, 32(1).

Goetz, A. M., \& Jenkins, R. (2001). Hybrid Forms of Accountability: Citizen Engagement in Institutions of Public-Sector Oversight in India. 
Public Management Review, 3(3).

Government of India (2006), Eleventh Five Year Plan, Vol. 2, Planning Commission, Government of India, New Delhi.

Government of India (2010) National Policy on Skill Development, Ministry of Labour \& Employment, Government of India.

Government of India (2010), Annual Report, 2009-10, Ministry of Labour and Employment, Government of India, New Delhi.

Government of India (2011), Mid Term Review of Eleventh Plan, Planning Commission, Government of India, New Delhi.

Government of India (2007), Vocational Training Improvement Project of Government of India, Project Implementation Plan, Directorate General of Employment and Training, Ministry of Labour and Employment, Government of India.

Government of India (2008), Economy Survey, 2007-08, Government of India, New Delhi.

Government of India (2009), National Skill Development Policy, Ministry of Labour and Employment, Government of India, New Delhi.

Govind Rajan Vijay (2007), Outlook Business, May 5.

Joshi, Anuradha (2010), Review of Impact and Effectiveness of Transparency and Accountability Initiatives, Project Report, Institute of Development Studies, Sussex.

Joshi, M; Joshi, N and Joshi, V, (2007), "Business War: Competitive Innovation Velocity", Ewing Marion Kauffman Foundation, USA. KPMG (2008), Entrepreneurial India, KPMG, New Delhi.

Malena, C, Forster, R. and Singh, J. (2004), Social Accountability: An Introduction to the Concept and Emerging Practice. Washington: The World Bank, Social Development Paper No. 76.

Mulgan, Richard, (2000), "'Accountability": An Ever Expanding Concept?', Public Administration, 78.

Mulgan, Richard, (2000), 'Comparing Accountability in the Public and Private sector', Australian Journal of Public Administration.

NKC (2008), Entrepreneurship in India, National Knowledge Commission, Government of India.

Paul, S. (2002), Holding the State to Account: Citizen Monitoring in Action. Books for Change, Bangalore.

Roberts, A. (2010), The First Four Years of India's Right to Information Act, Suffolk University Law School, www.ssrn.com. 
Roberts, Alasdair (2006), Blacked Out: Government Secrecy in the Information Age, Cambridge: Cambridge University Press.

Roberts, Alasdair (2010), The Logic of Discipline: Global Capitalism and the Architecture of Government. New York: Oxford University Press.

Schedler, A. (1999), "Conceptualizing Accountability" in A. Schedler, L. Diamond and M. Plattner eds. The Self Restraining State: Power and Accountability in New Democracies. Boulder, Co.: Lynne Riener.

Scott, Colin, (2000), 'Accountability in the Regulatory State', Journal of Law and Society, 27,1.

Seelos, Christian; Mair, Johanna; (2004), "Social Entrepreneurship the contribution of Individual Entrepreneurs to sustainable development", Working Paper 553, IESE Business School- Universidad de Navarra

SHRM (2011), Perspectives on Women in Management in India, Society for Human Resource Management, New Delhi.

Singh, A.K. (2009), Role of Entrepreneurship Development in Urban Poverty Alleviation, Training Module, Regional Centre for Urban and Environmental Studies, Lucknow.

Singh, A. K. etal. . (2012) Women Entrepreneurship Development in India, Serials Publications, New Delhi

Srinivasan, T.N. (2007), Hindu Business Line, April, 23.

Tripathi, Dwijendra (1984), Business Communities of India: A Historical perspective quoted by National Knowledge Commission, 2008, New Delhi.

Utz, A. (2005), Indian and the Knowledge Economy: The Role of Secondary Education, World Bank Institute, Washington, DC.

World Bank (2006), Skill Development in India: The Vocational Education and Training System, Human Development Unit, South Asia Region.

World Bank Institute (2006), General Social Accountability Concepts and Tools. Presentation by Karen Sirker. World Bank Institute: Washington DC. 